\title{
HIV Risks and Seroprevalence Among Mexican American Injection Drug Users in California
}

\author{
Alexis N. Martinez $\cdot$ Ricky N. Bluthenthal • \\ Neil M. Flynn • Rachel L. Anderson • \\ Alex H. Kral
}

Published online: 18 December 2009

(C) The Author(s) 2009. This article is published with open access at Springerlink.com

\begin{abstract}
Latinos in the United States are an ethnically diverse group disproportionately affected by HIV/AIDS. We describe HIV seroprevalence, HIV risk behaviors and utilization of health services among Mexican American injection drug users (IDUs) in California $(n=286)$ and compare them to White $(n=830)$ and African American $(n=314)$ IDUs. Study participants were recruited from syringe exchange programs $(n=24)$ in California. HIV seroprevalence among Mexican Americans $(0.5 \%)$ was dramatically lower than Whites (5\%) and African Americans (8\%). Mexican Americans reported fewer sex-related risks than Whites and African Americans though injectionrelated risks remained high. Compared to Whites, Mexican Americans were more likely to participate in drug treatment during a 6 month period (AOR 1.5, 95\% CI 1.1, 2.0) but less likely to receive any health care (AOR $0.6,95 \% \mathrm{CI}$ $0.5,0.8)$. Exploring cultural and structural factors among
\end{abstract}

A. N. Martinez ( $\square)$

Department of Sociology, San Francisco State University,

San Francisco, CA 94132, USA

e-mail: alexisnm@sfsu.edu

R. N. Bluthenthal

Health Program and Drug Policy Research Center,

RAND Corporation, Santa Monica, CA, USA

R. N. Bluthenthal

Urban Community Research Center, Sociology Department,

California State University at Dominguez Hills,

Carson, CA, USA

N. M. Flynn

Department of Internal Medicine, Division of Infectious

Diseases, University of California

Davis Medical Center, Davis, CA, USA
Mexican American IDUs may offer new insights into how to maintain low rates of HIV seroprevalence and reduce barriers to health care utilization.

Keywords Injection drug use - HIV/AIDS .

Mexican American - Syringe coverage - Drug treatment . Health care utilization

\section{Introduction}

Latinos in the United States (US) are disproportionately affected by the HIV/AIDS epidemic [1]. The prevention response to the epidemic among Latinos is complicated by the cultural, social, and geographic heterogeneity found within this diverse community [2,3]. Recent data suggest an increasing trend in HIV incidence among Latinos in California, of which Mexicans and Mexican Americans make up the largest ethnic group (83\% in 2007) $[4,5]$. As of December 2007, Latinos in California accounted for

\section{R. L. Anderson}

Sacramento Area Needle Exchange, Sacramento, CA, USA

A. H. Kral

Urban Health Program, RTI International, San Francisco,

CA, USA

A. H. Kral

Department of Family and Community Medicine, University of California, San Francisco, San Francisco, CA, USA 
$28 \%$ of total HIV cases and $36 \%$ of the total population compared to $24 \%$ of HIV cases and $35 \%$ of the population in 2004. Among all HIV tests administered at publicly funded sites in California in 2003, African American males had the highest infection rate at $2.74 \%$ followed by Latino males at $2.22 \%$ [6]. Men who have sex with men is already well established as a behavioral risk for HIV among Latinos in California [7, 8], though it is less clear how the dual risks of injection drug use (IDU) and men who have with men (MSM) are present among Latino, specifically Mexicans and Mexican-Americans, IDUs. Recent epidemiological data from public testing sites also suggest that HIV positivity in California is highest among Latino MSM who also inject drugs (5.2\%) [9].

Previous studies have identified Puerto Rican IDUs as a high risk Latino subgroup [10]. In 2002, 45\% of Puerto Rican IDUs in New York City were infected with HIV along with $44 \%$ of Black IDUs and $32 \%$ of White IDUs [11]. Among Puerto Rican IDUs, access to sterile syringes [12], incarceration [13], residential status [14], drug scene roles [15], and sexual identity [16] have been previously identified as important factors that influence HIV transmission. Comparatively, Mexican Americans have been shown to have higher rates of drug injection and lower rates of sharing injection paraphernalia than Puerto Ricans $[17,18]$. In addition to injection risk behavior, data from a national sample of IDUs suggested that Mexicans and Mexican Americans engage in less sexual risk behavior compared to Puerto Ricans [19].

Much of the current HIV prevention research on Mexicans or Mexican Americans in California focuses on the experiences of migrant workers and their needs as an economically impoverished and highly mobile population [20-24]. Although the seroprevalence of HIV is very low in Mexico overall $(0.3 \%)$, the HIV seroprevalence among a sample of IDUs in the border cities of Tijuana and Ciudad Juarez was found to be $1.9 \%$ and $4.1 \%$, respectively, in 2005 [22, 25]. Geographic clusters of high HIV seroprevalence, injection and sexual risk in border communities have potential implications for the HIV epidemic in California. Previous studies have identified acculturation as a contributing factor to increased drug use and sexual behavior $[23,26]$ though conflicting evidence exists for injection related HIV risk [27, 28]. Research suggests that mental health issues, changes in gender roles, increased access to alcohol and drugs, immigration dynamics and mobility, and reduced perceptions of HIV/AIDS risk can impact the vulnerability of immigrant Latino groups to HIV/AIDS [29]. Among a sample of migrant and marginally housed Latinos in California, injection drug use was reported by almost $30 \%$ of the sample that occurred among Mexican migrants due to the injection of illicit drugs and lay therapeutic injections of vitamins and medicines [30].
In addition to HIV risk behaviors, the utilization of health services, including drug treatment programs and frequencies of visits to services providers such as doctors and hospitals, is an important component of HIV prevention for IDUs. IDUs who use drug treatment programs typically reduce their risk for HIV infection [31, 32]. Research suggests that Latinos are in greater need of access to drug treatment programs than African Americans and Whites [33, 34]. Furthermore, a national survey showed that among those with perceived need, Latinos were more likely to have less care than needed or delayed care $(22.7 \%$ versus $10.7 \%)$ for alcoholism, drug abuse or mental health, compared to Whites [35]. Consistently documented disparities that show reduced access to health services among Latinos compared to Whites also raise important concerns for the health status of HIV-positive Latinos [36-40]. Over the past 10 years, Latinos have accounted for the largest increase in the number of persons living with AIDS in California [9].

Using data from the California Syringe Exchange Program Study (CalSEP), we described HIV seroprevalence, HIV risk behaviors and utilization of health services among a geographically diverse sample of IDUs recruited from all syringe exchange programs (SEPs) in the state of California between 2001 and 2003. Understanding the context of HIV risk among Mexican American IDUs will contribute to our understanding of the prevention needs of a high risk yet health-seeking group of Latinos in California, and how these needs may differ from Whites and African Americans. Understanding the context of HIV risk among Mexican American IDUs will contribute to the literature on how and why their HIV prevention needs may differ from whites and African Americans.

\section{Methods}

Participants

The CalSEP study sampled clients from all 24 SEPs in operation during the study period. The SEPs were located in 16 California counties. A cross-section of SEP clients was sampled from each of the SEPs annually from 2001 to 2003. Each SEP was sampled in three consecutive annual samples, with the exception of two counties which were only sampled twice.

SEP clients were approached at sites by research staff and were eligible for study participation if they reported injecting drugs in the past 30 days. Due to the illegal status of several SEPs in our sampling frame as well as limited SEP hours and negative prior experience with research studies that attempted to randomize eligible study participants at their program, SEPs and the research team decided to use convenience sampling. 
The standardized interview elicited information about demographics, socioeconomic status, drug use history and practices, access to health care and drug treatment, and HIV-related risk behaviors such as sharing of injection paraphernalia and sexual behaviors. Answers were entered by interviewers into Questionnaire Development System (QDS) software program (QDS, NOVA Research Inc., Bethesda, MD) on lap-top computers to reduce the likelihood of data entry errors by coordinating skip patterns and running consistency and validity checks. After the interview, each participant received HIV risk reduction counseling, an oral HIV test and referrals to social and medical services specific to the county where the research was being conducted. Each participant was paid $\$ 10$ for participating in the study. HIV test results and follow-up counseling were scheduled for one to 2 weeks later in the same location where the interviews and HIV testing had taken place.

\section{Measures}

\section{Race/Ethnicity}

To ascertain information about race/ethnicity, participants were asked the following question by an interviewer: "What do you consider to be your primary race or ethnicity?" and were offered eight distinct categories from which to choose an answer. If participants chose Latino, a subsequent question was asked to determine if they were (1) Mexican American/Chicano, (2) Mexican, (3) Puerto Rican, (4) Cuban, (5) Central or South American, (6) Dominican Republic or (7) Other. Of all study participants in CalSEP $(N=1,588), 317(20 \%)$ self-identified as Latino. About $87 \%$ of the Latino IDUs $(n=286)$ specified their ethnicity to be Mexican American $(n=235)$ or Mexican $(n=51)$. The remaining $13 \%(n=30)$ of those who identified as Latino include individuals of Puerto Rican, Central or South American, Cuban or Dominican Republican origin. After excluding the non-Mexican Latinos, we were left with a final sub-sample of $n=286$. For the remainder of this paper, we refer to IDUs as Mexican American if they identified as either Mexican or Mexican American/Chicano. IDUs who reported that they were either Non-Hispanic White $(n=830)$ or African American $(n=314)$ are included as comparison groups for a final sample $(N=1,430)$.

\section{Individual Level Variables}

Measurement of additional individual variables is described in Table 1. Syringe coverage was measured by multiplying the number of syringes retained (syringes they did not intend to give, sell or trade to someone else) from their last SEP visit by their monthly SEP visits and dividing this total by their total drug injections (including intravenous, subcutaneous and intramuscular) in the last 30 days [41]. The resulting figure was multiplied by 100 to generate a percentage of syringe coverage for each participant- $150 \%$ coverage or more, 100-149\%, 50-99\%, and less than $50 \%$ coverage [41].

\section{Zip Code Level Variables}

Participants were asked to give their zip code of residence during the interview regardless of their housing status. We linked zip code level data from the United States Census 2000 to zip codes given by each CalSEP participant as their place of residence. Of the final sample $(N=1,430), 82 \%$ were included in the zip code level analyses. No significant differences were identified between the characteristics of participants with missing zip code data and participants without missing data. The medians and inter-quartiles ranges of select zip code level social and economic indicators are compared for Mexican American IDUs, White IDUs and African American IDUs using the KruskalWallis test (Table 3).

\section{Outcome Variables}

The four outcome variables in this analysis are all dichotomous variables that include (1) syringe sharing, (2) unprotected vaginal or anal sex, (3) utilization of health care, and (4) utilization of drug treatment. Syringe sharing was defined as distributive or receptive syringe sharing at least one time in the past 30 days. Unprotected vaginal or anal sex is defined as any vaginal sex, penetrative anal sex or receptive anal sex without a latex condom. Health service utilization was measured in two ways: (1) any health care in the past 6 months and (2) any drug treatment in the past 6 months. Utilization of drug treatment was defined as any use (yes/no) of multiple types of treatment modalities including methadone detoxification, methadone maintenance, non-methadone outpatient treatment, residential treatment, and 12-step self-help in the past 6 months. Finally, utilization of health care was defined as any use (yes/no) in the past 6 months.

\section{Data Analyses}

Individual level categorical variables by racial/ethnic group were compared using Pearson's Chi-Square test of Association (Table 1). Individual level continuous variables (age, education, frequency of injections, frequency of SEP use) by racial/ethnic group were compared using either one-way analysis of variance (ANOVA) or Kruskal-Wallis test, depending on the skewness of the frequency 
Table 1 Characteristics of Mexican American IDUs, CalSEP study, 2001-2003

\begin{tabular}{|c|c|c|c|c|}
\hline & $\begin{array}{l}\text { Mexican American } \\
(N=286)\end{array}$ & $\begin{array}{l}\text { White } \\
(N=830)\end{array}$ & $\begin{array}{l}\text { African American } \\
(N=314)\end{array}$ & $\begin{array}{l}\text { Chi-square } \\
\left(\chi^{2}\right)\end{array}$ \\
\hline \multicolumn{5}{|l|}{ Drug-related } \\
\hline Heavy alcohol use ** $^{*}$ & $53 \%$ & $35 \%$ & $30 \%$ & 46.8 \\
\hline Smoked crack cocaine in past 30 days** & $28 \%$ & $21 \%$ & $50 \%$ & 89.5 \\
\hline Injected heroin in past 30 days** & $94 \%$ & $71 \%$ & $90 \%$ & 87.3 \\
\hline Injected methamphetamine in past 30 days** & $10 \%$ & $48 \%$ & $15 \%$ & 196.4 \\
\hline Median (IQR) injections in past 30 days** & $90(35,122)$ & $65(28,120)$ & $70(30,120)$ & 8.7 \\
\hline Median (IQR) use of SEP in past 6 months** & $15(5,24)$ & $12(4,24)$ & $22(6,24)$ & 19.4 \\
\hline Syringe coverage $(100 \%+)^{* *}$ & $40 \%$ & $47 \%$ & $52 \%$ & 8.7 \\
\hline \multicolumn{5}{|l|}{ HIV-related } \\
\hline HIV antibody positive** & $0.7 \%$ & $5 \%$ & $8 \%$ & 18.8 \\
\hline Receptive syringe sharing in past 30 days $* *$ & $23 \%$ & $26 \%$ & $12 \%$ & 26.3 \\
\hline Distributive syringe sharing in past 30 days** & $31 \%$ & $29 \%$ & $15 \%$ & 26.6 \\
\hline Reused needles in past 30 days** & $68 \%$ & $48 \%$ & $56 \%$ & 26.4 \\
\hline Shared rinse water in past 30 days** & $49 \%$ & $40 \%$ & $29 \%$ & 25.0 \\
\hline Shared cooker in past 30 days* & $60 \%$ & $52 \%$ & $51 \%$ & 6.8 \\
\hline Unprotected vaginal/anal sex in past 30 days & $62 \%$ & $59 \%$ & $55 \%$ & 4.5 \\
\hline Traded sex for cash or drugs in past 6 months* & $6 \%$ & $12 \%$ & $11 \%$ & 9.5 \\
\hline Men having sex with men in past 6 months & $2 \%$ & $4 \%$ & $5 \%$ & 2.8 \\
\hline Steady IDU sex partner in past 6 months* & $25 \%$ & $38 \%$ & $30 \%$ & 19.7 \\
\hline \multicolumn{5}{|l|}{ Health-related } \\
\hline History of abscess in past 12 months & $48 \%$ & $41 \%$ & $40 \%$ & 6.5 \\
\hline Self-report Hepatitis C positive & $53 \%$ & $53 \%$ & $48 \%$ & 1.3 \\
\hline History of drug overdose in past 12 months** & $11 \%$ & $7 \%$ & $15 \%$ & 15.7 \\
\hline Received any drug treatment in past 6 months $* *$ & $41 \%$ & $31 \%$ & $28 \%$ & 13.4 \\
\hline Received any health care in past 6 months** & $47 \%$ & $57 \%$ & $64 \%$ & 25.2 \\
\hline
\end{tabular}

$* P<.05 ; * * P<.01$

distribution. Bivariate logistic regression was used to identify variables significantly associated with both race/ ethnicity (Mexican American, White and African American) and the main outcomes at the $P<.10$ level. Significant variables were entered as control variables in multivariate logistic regression models. We hypothesized that the availability of drug treatment services would differ significantly by SEP location $(n=23)$ and sought to adjust for this potential bias in the multivariate model rather than explicitly measure its effect on the outcome. To adjust for these potential biases, we entered 23 dummy variables into the multivariate logistic regression model. Final models retained all variables that remained significant at the $P<.05$ level (Table 2).

\section{Results}

Based on HIV tests conducted at time of interview, HIV seroprevalence was $0.7 \%$ (2/286) among Mexican
American IDUs, 5\% among White IDUs and 8\% among African American IDUs. In spite of this dramatic difference in HIV seroprevalence by race/ethnicity, the prevalence of behaviors related to injection risk among Mexican American IDUs were similar to White IDUs and significantly higher than African American IDU (Table 1). The prevalence of distributive and receptive syringe sharing reported by Mexican American IDUs was not significantly different than White IDUs. However, the prevalence of syringe reuse, sharing of cookers and rinse water was significantly higher among Mexican Americans compared to White IDUs. No significant differences across racial/ ethnic groups were observed for unprotected vaginal or anal sex, though some interesting differences in sex-related risks were noted. Compared to both Whites and African Americans, Mexican American IDUs reported the lowest 6-month prevalence of sex-related risks, including trading sex for cash or drugs, MSM, and steady sexual partners who are IDUs. Because race/ethnicity did not remain significantly associated with syringe sharing (either 
Table 2 Multivariate analysis ${ }^{\mathrm{a}}$ of ethnic differences in health services among IDUs, CalSEP study, 2001-2003

\begin{tabular}{ll}
\hline & $\begin{array}{l}\text { Adjusted odds ratio } \\
\text { (95\% confidence } \\
\text { interval) }\end{array}$ \\
\hline $\begin{array}{l}\text { Received any health care in past } 6 \text { months } \\
\text { Mexican American** }\end{array}$ & $0.6(0.5,0.8)$ \\
White & $\begin{array}{l}\text { Referent } \\
\text { African American }\end{array}$ \\
Male** & $0.73(0.50,0.99)$ \\
History of abscess in past 12 months $* *$ & $0.64(0.50,0.82)$ \\
History of drug overdose in past 12 months** & $1.96(1.6,2.5)$ \\
Years of education** & $1.7(1.2,2.4)$ \\
HIV antibody status** & $3.1(1.6,6.0)$ \\
Received drug treatment in past 6 months & $1.5(1.1,2.0)$ \\
Mexican American** & Referent \\
White & $0.84(0.6,1.1)$ \\
African American & $1.5(1.2,1.9)$ \\
History of abscess in past 12 months** &
\end{tabular}

${ }^{\text {a }}$ Adjusted odds ratios were estimated using multivariate logistic regression

$* P<.05 ; * * P<.01$

distributive or receptive) or unprotected vaginal or anal sex in the final model (results not shown), we do not present the results of our multivariate analysis.

Overall, our sample of Mexican American IDUs had a median age of 44 years (IQR 35, 50), a median injection drug use history of 21 years (IQR 9,30) and a $46.9 \%$ prevalence of current homelessness. Regarding sociodemographic variables, our sub-sample of Mexican Americans included more men compared to our sub-sample of Whites $\left(77.6 \%\right.$ men compared to $63.6 \% ; \chi^{2}=19.2$, $N=1,106, P<.01)$, had fewer mean years of education than Whites and African Americans (10.7 years, $\mathrm{SD}=2.3$ compared to 12.2 years, $\mathrm{SD}=2.2$ and 12 years, $\mathrm{SD}=1.7 ; F=54.1, N=1,419, P<.01)$ and reported a higher prevalence of arrest in the past 6 months than Whites $\left(23.7 \%\right.$ compared to $31.4 ; \chi^{2}=5.9, N=1,100$, $P=.015)$ and a lower prevalence of arrest than African Americans (23.7\% compared to $18.8 \%$; not significant). Table 1 presents drug-related, health-related and HIVrelated individual variables by race/ethnicity. The highest prevalence of heroin injection and the lowest prevalence of methamphetamine injection were reported by Mexican American IDUs. Regardless of drug type, Mexican American IDUs reported the highest median number of injections in a 30 day period. Mexican Americans also reported the heaviest alcohol use in the past 30 days.

Bivariate analyses identified significant differences between race/ethnicity and use of health services. Recent use (6 month) of any drug treatment was highest among
Mexican American IDUs compared to White IDUs or African American IDUs. The association between race/ ethnicity and drug treatment remained statistically significant in multivariate analysis (Table 2). Compared to White IDUs, Mexican American IDUs have higher odds of using drug treatment in the past 6 months (AOR 1.6, 95\% CI 1.1, 2.1). The Hosmer-Lemeshow goodness-of-fit test showed satisfactory model-data fit $\left(\chi^{2}(4)=8.0, P=.1\right)$. Conversely, Mexican American IDUs reported the lowest percentage of using health care for any reason (separate from drug treatment), compared to White or African American IDUs. Again, the association between race/ethnicity and use of any health care remained statistically significant after controlling for additional individual level variables (Table 2). Mexican American IDUs had lower adjusted odds of using any health care in a 6 month period compared to White IDUs (AOR 0.6, 95\% CI 0.5, 0.8). The Hosmer-Lemeshow goodness-of-fit test showed satisfactory model-data fit $\left(\chi^{2}(8)=11.3, P=.19\right)$.

We were secondarily interested in reported frequency of SEP use and levels of syringe coverage (Table 1). Several significant differences were noted. Though Mexican American IDUS reported a similar frequency of SEP use than White IDUs during the past 6 months, Mexican American IDUs had the lowest levels of $100 \%+$ syringe coverage compared to both Whites and African Americans.

Table 3 presents the median percentages of zip code level variables by race/ethnicity. Our data suggest that Mexican American IDUs live in zip codes that have a majority of Hispanic residents; in comparison, Whites and African Americans lived in zip codes with significantly fewer Hispanic residents. The median percentage of households living under the poverty level was also lower in zip codes where Mexican American IDUs live than that of Whites and African Americans, as is the percentage of female headed households.

\section{Discussion}

We present data on HIV risk behaviors and HIV seroprevalence among Mexican American, White and African American IDUs. Similar to recent studies of HIV seroprevalence among Mexican IDUs on the US/Mexico border [21, 22, 25], HIV seroprevalence was extremely low $(0.7 \%)$ in our sample. Sexual risks might help explain why Mexican American IDUs in our sample have such a low HIV prevalence in spite of having equal levels of syringe sharing and lower access to sterile syringes than Whites and African Americans [42, 43]. Reports of trading sex for cash or drugs $(6 \%)$ and injection of methamphetamines (10\%) were significantly lower for Mexican Americans IDUs than Whites and African Americans. Though not 
Table 3 Zip code level characteristics of IDUs by ethnicity, CalSEP study, 2001-2003

\begin{tabular}{llccc}
\hline Census 2000 variables & $\begin{array}{l}\text { Mexican American } \\
(N=238)(\%)\end{array}$ & White $(N=649)(\%)$ & $\begin{array}{l}\text { African American } \\
(N=287)(\%)\end{array}$ & $\begin{array}{l}\text { Kruskal-Wallis } \\
\text { test statistic }\end{array}$ \\
\hline Median 'Hispanic' ethnicity** & 51.8 & 21.9 & 29.1 & 199.6 \\
Median households below poverty level** & 14.7 & 23.6 & 19.4 & 134.8 \\
Median households on public assistance** & 7.3 & 3.9 & 9.6 & 11.3 \\
Median unemployed males in labor force** & 8.6 & 6.5 & 12.9 & 13.9 \\
Median vacant housing & 14.4 & 52.3 & 60.3 & 49.7 \\
Median housing occupied by renters** & 54.1 & 8.2 & 6.6 & 30.3 \\
Median female headed households** & 3.9 & 48 & 50 & 159.9 \\
Median households in same house as 1995 & 51 & & 18.1 \\
\hline
\end{tabular}

${ }^{\text {a }}$ Degrees of freedom equal two for all statistical tests

** $P<.01$

statistically significant, Mexican American IDUs in our sample reported the smallest prevalence of men having sex with other men (2\%). It is plausible to suggest that HIV has remained low among our sample of Mexican American IDUs because it is being transmitted primarily among subpopulations with a high prevalence of sexual risk behaviors such as MSM.

Syringe coverage for Mexican Americans, or the percentage of one shot for one syringe coverage, was significantly lower than coverage for Whites and AfricanAmericans (Table 1). Individual syringe coverage has been strongly associated with safer injection behaviors, including lower odds of syringe sharing [41]. The high prevalence of abscess, overdose and Hepatitis $\mathrm{C}$ among Mexican American IDUs suggests that injection risk behaviors, although not resulting in a high HIV seroprevalence, are detrimental to the health status of this population. These findings, coupled with the high frequency of total injections and low levels of $100+$ syringe coverage, make it important to further study injection-related risks of Mexican American IDUs.

Our data suggest that Mexican American IDUs are at risk for injection-related non-HIV related health outcomes, and given the higher reported use of drug treatment, we emphasize the incorporation or strengthening of prevention efforts to reduce abscesses, overdose and Hepatitis $\mathrm{C}$ at drug treatment facilities. Previous studies have convincingly demonstrated that methadone treatment is an effective way to prevent HIV [44-47], though it is more likely that a lack of sexual risk accounted for the dramatically low seroprevalence observed in our sample of Mexican American IDUs. Regardless, linkages with prevention services such as drug treatment represent the opportunity to reinforce prevention of sex-related HIV risk and expand prevention efforts for injection-related non-HIV health risks. It is unclear why Mexican Americans are accessing drug treatment programs in greater numbers than Whites and African Americans. Referrals from SEPs, cultural differences in responding to drug use and abuse, or geographic availability of treatment services may explain the observed differences [48]. Structural factors such as neighborhood dynamics and composition, including social norms and economic disadvantage may also contribute to access and utilization of drug treatment programs. Our zip code level census data suggests that Mexican American IDUs reside in ethnically homogenous communities and warrants a more detailed analysis of HIV prevention services available in Latino neighborhoods. A recent study in Los Angeles found that racial differences in treatment completion were related to differences in levels of neighborhood disadvantage [49]. Our geographic data also showed that zip codes where Mexican American IDUs reside had a lower percentage of residents living under the poverty level than zip codes where White and African American IDUs reside.

The higher odds of using drug treatment in the past 6 months are contrasted with the lower odds of using any health care in the past 6 months regardless of job status, education, income level, and past medical histories of abscess and overdose. Overall, our data is consistent with research in the United States and California that shows Latinos are less likely to utilize health care [38, 40]. Our participants overwhelmingly chose to conduct their interviews in English (99\%) which makes it unlikely that our participants would experience language barriers to accessing health care as is often reported in the literature [50]. However, we did not assess the immigration status or geographic mobility of our participants. No significant differences in socio-demographics were noted between our participants who identified as Mexican compared to those who identified as Mexican American. It is possible that perceived issues of documentation might negatively impact 
utilization of health care in a way that is not experienced when accessing drug treatment programs. Our study participants may not have access to culturally competent health care services that also address their stigmatized identities as IDUs. Because Latinos with HIV/AIDS in California are at risk for poor health outcomes compared with Whites [51], determining barriers to care in high risk groups such as our study population carries significant implications if HIV incidence begins to increase. Improving linkages with health care providers might also be crucial for those in need of specialized care related to drugrelated conditions such as Hepatitis C, endocarditis, abscesses and overdoses.

\section{Study Limitations}

There are several limitations in study design that should be considered when interpreting the results of this study. The CalSEP study was not designed to specifically recruit or study IDUs of Mexican descent. Thus we are not able to study many relevant variables that might explain our findings and differences between ethnic groups. Our study is cross-sectional in design and therefore we cannot assess causal relationships between predictors and outcomes. Social desirability might have differentially impacted the self-report of behaviors across ethnic groups. Selection of our study participants at SEPs limits our findings to IDUs already accessing community-based HIV prevention services. It is also possible that illegal immigrants from Mexico and Spanish monolingual speakers were biased to inclusion in our sample because of our computer-based data collection methods (QDS). Finally, our study is limited by the convenience sample framework used to recruit IDUs into our study. However, the illegal status of several SEPs in our study, coupled with the limited hours of SEP operation, prevented us from using methods of random sampling to recruit IDUs into our study.

Our data has taken some first steps at understanding how and why the HIV prevention needs of Mexican American IDUs may differ from White and African American IDUs, though it is limited in its ability to tease out some of the issues that deserve further consideration. More research should be done to explore the role of neighborhoods and communities in the lives of our participants, including how far they may travel to access SEPs, drug treatment programs and other forms of health services, what level of drug-related disclosure exists with families and friends, and how injection practices are negotiated in social and sexual networks. Exploring the intersection of cultural and structural factors in the lives of Mexican American IDUs may offer new insights into how to reduce injection-related risk behaviors, keep HIV seroprevalence low, and reduce barriers to health care utilization.
Acknowledgments The authors would like to thank the Centers for Disease Control and Prevention for funding the California Syringe Exchange Program Study (Grant\# R06/CCR918667) and the National Institute of Drug Abuse (Grant \#DA14210). We would like to thank project coordinators Mary-Lou Gilbert and Andrea Scott, the SEPs and their clients that participated in this study.

Open Access This article is distributed under the terms of the Creative Commons Attribution Noncommercial License which permits any noncommercial use, distribution, and reproduction in any medium, provided the original author(s) and source are credited.

\section{References}

1. Amaro H, Arevalo S, Gonzalez G, Szapocznik J, Iguchi MY. Needs and scientific opportunities for research on substance abuse treatment among hispanic adults. Drug Alcohol Depend. 2006;84(Supp 1):64-75.

2. Gonzalez JS, Hendriksen ES, Collins EM, Durán RE, Safren SA. Latinos and HIV/AIDS: examining factors related to disparity and identifying opportunities for psychosocial intervention research. AIDS Behav. 2008;13(3):582-602.

3. Deren S, Shedlin M, Decena CU, Mino M. Research challenges to the study of HIV/AIDS among migrant and immigrant hispanic populations in the United States. J Urban Health. 2005;82(2): III13-25.

4. US Census Bureau. American fact finder data tables. 2000. Accessed 11 Dec 2008.

5. Office of AIDS. HIV/AIDS among California Latinos. Sacramento; 2008 Oct.

6. Office of AIDS. California HIV counseling and testing annual report, January-December 2003. Sacramento: California Department of Health Services; 2006.

7. Centers for Disease Control and Prevention. HIV/AIDS among Hispanics/Latinos. Atlanta; 2007 Aug.

8. Diaz RM. Latino gay men and HIV: culture, sexuality, and risk behavior. Routledge; 1997.

9. Facer M. A brief profile of HIV/AIDS among Latinos in California. Sacramento: California Department of Public Health, Office of AIDS; 2006.

10. Battjes RJ, Pickens RW, Haverkos HW, Sloboda Z. HIV risk factors among injecting drug users in five US cities. AIDS. 1994;8(5):681-7.

11. Kottiri BJ, Friedman SR, Neaigus A, Curtis R, Des Jarlais DC. Risk networks and racial/ethnic differences in the prevalence of HIV infection among injection drug users. J Acquir Immune Defic Syndr. 2002;30(1):95-104.

12. Finlinson HA, Oliver-Velez D, Deren S, et al. A longitudinal study of syringe acquisition by Puerto Rican injection drug users in New York and Puerto Rico: implications for syringe exchange and distribution programs. Subst Use Misuse. 2006a;41(9):1313-36.

13. Kang SY, Deren S, Andia J, Colon HM, Robles R, Oliver-Velez D. HIV transmission behaviors in jail/prison among Puerto Rican drug injectors in New York and Puerto Rico. AIDS Behav. 2005;9(3):377-86.

14. Andia JF, Deren S, Kang SY, et al. Residential status and HIV risk behaviors among Puerto Rican drug injectors in New York and Puerto Rico. Am J Drug Alcohol Abuse. 2001;27(4):719-35.

15. Friedman SR, Kang SY, Deren S, Robles R, et al. Drug-scene roles and HIV risk among Puerto Rican injection drug users in East Harlem, New York and Bayamon, Puerto Rico. J Psychoactive Drugs. 2002;34(4):363-9.

16. Finlinson HA, Colon HM, Robles RR, Soto M. Sexual identity formation and AIDS prevention: an exploratory study of non-gay- 
identified Puerto Rican MSM from working class neighborhoods. AIDS Behav. 2006b;10(5):531-9.

17. Estrada AL. Drug use and HIV risks among African-American, Mexican-American, and Puerto Rican drug injectors. J Psychoactive Drugs. 1998;30(3):247-53.

18. Estrada AL. Health disparities among African-American and Hispanic drug injectors-HIV, AIDS, Hepatitis B virus and Hepatitis C virus: a review. AIDS. 2005;19(Suppl 3):S47-52.

19. Montoya ID, Bell DC, Richard AJ, Carlson JW, Trevino RA. Estimated HIV risk among Hispanics in a national sample of drug users. J Acquir Immune Defic Syndr. 1999;21(1):42-50.

20. Hernandez M, Lemp G, Castaneda X, et al. HIV/AIDS among mexican migrants and recent immigrants in California and Mexico. J Acquir Immune Defic Syndr. 2004;37(Supplement 4):S203.

21. Patterson TL, Semple SJ, Fraga M, et al. Comparison of sexual and drug use behaviors between female sex workers in Tijuana and Ciudad Juarez, Mexico. Subst Use Misuse. 2006;41(10-12): 1535-49.

22. Brouwer KC, Strathdee SA, Magis-Rodriguez C, et al. Estimated numbers of men and women infected with HIV/AIDS in Tijuana, Mexico. J Urban Health. 2006;83(2):299-307.

23. Sanchez M, Lemp G, Magis-Rodriguez C, Bravo-Garcia E, Carter S, Ruiz JD. The epidemiology of HIV among Mexican migrants and recent immigrants in California and Mexico. J Acquir Immune Defic Syndr. 2004;37(Supplement 4):204-14.

24. Organista KC, Carrillo H, Ayala G. HIV prevention with Mexican migrants: review, critique, and recommendations. J Acquir Immune Defic Syndr. 2004;37(Suppl 4):S227-39.

25. Frost SD, Brouwer KC, Firestone Cruz MA, et al. Respondentdriven sampling of injection drug users in two U.S.-Mexico border cities: recruitment dynamics and impact on estimates of HIV and syphilis prevalence. J Urban Health. 2006;83(Suppl 7):83-97.

26. Vega WA, Alderete E, Kolody B, Aguilar-Gaxiola S. Illicit drug use among Mexicans and Mexican Americans in California: the effects of gender and acculturation. Addiction. 1998;93(12): 1839-50.

27. Zule WA, Desmond DP, Medrano MA, Hatch JP. Acculturation and risky injection practices among hispanic injectors. Eval Program Plann. 2001;24(2):207-14.

28. Valdez A, Neaigus A, Cepeda A. Potential risk factors for injecting among Mexican American non-injection heroin users. J Ethn Subst Abuse. 2007;6(2):49-73.

29. Shedlin MG, Drucker E, Decena CU, et al. Immigration and HIV/ AIDS in the New York metropolitan area. J Urban Health. 2006;83(1):43-58.

30. Denner J, Organista KC, Dupree JD, Thrush G. Predictors of HIV transmission among migrant and marginally housed Latinos. AIDS Behav. 2005;9(2):201-10.

31. Gowing LR, Farrell M, Bornemann R, Sullivan LE, Ali RL. Brief report: methadone treatment of injecting opioid users for prevention of HIV infection. J Gen Intern Med. 2006;21(2):193-5.

32. Sullivan LE, Metzger DS, Fudala PJ, Fiellin DA. Decreasing international HIV transmission: the role of expanding access to opioid agonist therapies for injection drug users. Addiction. 2005; 100(2):150-8.

33. De La Rosa MR, Holleran LK, Rugh D, MacMaster SA. Substance abuse among U.S. Latinos: a review of the literature. Haworth Social Work Practice Press; 2005.

34. Substance Abuse and Mental Health Administration. National household survey on drug abuse, summary of findings; 2002.
35. Wells K, Klap R, Koike A, Sherbourne C. Ethnic disparities in unmet need for alcoholism, drug abuse and mental health care. Am J Psych. 2001;158(12):2027-32.

36. Alegria M, Page JB, Hansen H, et al. Improving drug treatment services for Hispanics: research gaps and scientific opportunities. Drug Alcohol Depend. 2006;84S:S76-84.

37. Haas JS, Phillips KA, Sonneborn D, et al. Variation in access to health care for different racial/ethnic groups by the racial/ethnic composition of an individual's county of residence. Med Care. 2004;42(7):707-14

38. Bliss EB, Meyers DS, Phillips KA, Fryer GE, Dovey SM, Green LA. Variation in participation in health care settings associated with race and ethnicity. J Gen Intern Med. 2004;19(9):931-6.

39. Ortiz L, Arizmendi L, Cornelius J. Access to health care among Latinos of Mexican descent in colonias in two Texas counties. $\mathrm{J}$ Rural Health. 2004;20(3):246-52.

40. Center for Health Policy Research. Policy research report: racial and ethnic disparities in access to health insurance and health care. Los Angeles: University of California; 2000.

41. Bluthenthal R, Anderson R, Flynn N, Kral A. Higher syringe coverage is associated with lower odds of HIV risk and does not increase unsafe syringe disposal among syringe exchange program clients. Drug Alcohol Depend. 2007;89:214-22.

42. Kral AH, Bluthenthal RN, Lorvick J, Gee L, Bacchetti P, Edlin BR. Sexual transmission of HIV-1 among injection drug users in San Francisco, USA: risk-factor analysis. Lancet. 2001;357(9266): 1397-401.

43. Maxwell JC, Cravioto P, Galvan F, Ramirez MC, Wallisch LS, Spence RT. Drug use and risk of HIV/AIDS on the Mexico-USA border: a comparison of treatment admissions in both countries. Drug Alcohol Depend. 2006;82(Suppl 1):S85-93.

44. Drucker E, Lurie P, Wodak A, Alcabes P. Measuring harm reduction: the effects of needle and syringe exchange programs and methadone maintenance on the ecology of HIV. AIDS. 1998;12(Suppl A):S217-30.

45. Metzger DS, Navaline H, Woody GE. Drug abuse treatment as AIDS prevention. Public Health Rep. 1998;113(Suppl 1):97-106.

46. Metzger DS, Navaline H. Human immunodeficiency virus prevention and the potential of drug abuse treatment. Clin Infect Dis. 2003;37(Suppl 5):S451-6.

47. Deren S, Kang SY, Colon HM, Robles R. Predictors of injection drug use cessation among Puerto Rican drug injectors in New York and Puerto Rico. Am J Drug Alcohol Abuse. 2007; 33(29):291-9.

48. Heinzerling KG, Kral AH, Flynn NM, et al. Unmet need for recommended preventive health services among clients of California syringe exchange programs: implications for quality improvement. Drug Alcohol Depend. 2006;81(2):167-78.

49. Jacobson JO, Robinson P, Bluthenthal RN. A multilevel decomposition approach to estimate the role of program location and neighborhood disadvantage and racial disparities in treatment completion. Soc Sci Med. 2007;64(2):462-76.

50. Jacobs E, Shephard D, Suaya J, Stone E. Overcoming language barriers in health care: costs and benefits of interpreter services. Am J Pub Health. 2004;94:866-9.

51. Solorio MR, Currier J, Cunningham W. HIV health care services for Mexican migrants. J Acquir Immune Defic Syndr. 2004; 37(4):S240-51. 